\title{
Diagnosing Causes of Water Scarcity in Complex Water Resources Systems and Identifying Risk Management Actions
}

\author{
Francisco Martin-Carrasco • Luis Garrote • \\ Ana Iglesias • Luis Mediero
}

\begin{abstract}
From the water management perspective, water scarcity is an unacceptable risk of facing water shortages to serve water demands in the near future. Water scarcity may be temporary and related to drought conditions or other accidental situation, or may be permanent and due to deeper causes such as excessive demand growth, lack of infrastructure for water storage or transport, or constraints in water management. Diagnosing the causes of water scarcity in complex water resources systems is a precondition to adopt effective drought risk management actions. In this paper we present four indices which have been developed to evaluate water scarcity. We propose a methodology for interpretation of index values that can lead to conclusions about the reliability and vulnerability of systems to water scarcity, as well as to diagnose their possible causes and to propose solutions. The described methodology was applied to the Ebro river basin, identifying existing and expected problems and possible solutions. System diagnostics, based exclusively on the analysis of index values, were compared with the known reality as perceived by system managers, validating the conclusions in all cases.
\end{abstract}

Keywords Water resources planning · Water scarcity Scarcity indices · Ebro river

\section{Introduction}

Proactive drought risk management may be developed along two non-excluding courses of action. On the one hand, measures to avoid drought-induced water scarcity should be identified, prioritised and implemented. Timely availability of these means increases the 
reliability of water resources systems to droughts and avoids demand deficits. On the other hand, mitigation actions should be planned to be taken while the drought is developing. Mitigation actions may reduce the system's vulnerability to droughts by reducing the magnitude of damages through management strategies and administrative measures.

In recent years, the application of system analysis techniques to evaluate the performance of water resources systems under different management alternatives has experienced significant advances. However, not much work has been published on the definition of practical performance indices since the three classic reliability, resiliency, and vulnerability indicators (Hashimoto et al. 1982), later combined as an indicator of sustainability (Loucks 1997).

Several indices are found in the literature related to droughts and water scarcity. The term drought refers to a temporary deviation from a long-term average in a hydrological context with regard to water supply. It usually originates in a considerable reduction in precipitation over a significant period of time and with a substantial spatial extent. The term water scarcity indicates a shortage of water to supply demands. Not all droughts imply water scarcity, since water infrastructures and contingency plans may overcome drought events. On the other hand, not always water scarcity is generated by droughts; it could also be generated by fast increase of water demands, associated with population growth or an extension of irrigated agriculture.

Most of the indices related to droughts and water scarcity have been developed for drought identification purposes, focused on meteorological drought as the triggering phenomenon of water scarcity. The main objectives of these indices are to establish the onset of drought and to evaluate its severity in terms of intensity, duration, and spatial extent (Guttman 1998; McKee et al. 1993; Quiring and Papakryiakou 2003). But prolonged absence of precipitation does not necessarily mean scarcity in a water resources system, because water demands can also be supplied from natural or artificial reservoirs where it has been conveniently stored: snowpack, aquifers, and regulation dams. Other indices, such as the Reclamation Drought Index and the Surface Water Supply Index (Shafer and Dezman 1982; Garen 1993) combine climate and water supply factors, including snowpack and reservoir levels, but they are focused on water availability and do not account for water demands.

The water shortage, although is usually originated by a meteorological phenomenon, it is conditioned by other time-varying factors, such as demand development, supply infrastructure, and management strategies (Wilchfort and Lund 1997). Scarcity indices (Ohlsson 2000) and shortage indices (Hsu 1995), that account for infrastructure, demands, and operating rules, have been proposed. These indices are relevant for decision makers to predict problems, but they are limited in scope and do not provide enough information to diagnose the causes of water scarcity or to identify possible solutions.

This paper reports the results of a research project undertaken to improve the effectiveness of water resources systems analysis as a tool for drought contingency planning. The paper provides a framework for theoretical analysis. The framework comprises a set of four indices that must be used in conjunction to quantify the severity of potential water scarcity problems in a system, to diagnose its causes, and to anticipate possible solutions. Empirical results are reported for a detailed case study: the Ebro river basin $\left(85,000 \mathrm{~km}^{2}\right)$ in northeast Spain.

\section{Proposed Indices for Water Scarcity Management}

Water scarcity is analysed by identifying demands which are not fully satisfied by the available water resources. The distribution of resources among multiple demands is a 
challenging task. In a large system, mathematical simulation and optimization models are used to obtain quantitative results accounting for all system complexities in an uncertain context. These models provide guidance for identifying unsatisfied demands, evaluating the effect of capacity building or water conservation measures, and scheduling available actions (Cai et al. 2002). All models provide a measure of demand reliability, quantified as the probability that a given demand may suffer water shortages during the planning horizon. This (or an equivalent) reliability index is used for decision making, identifying the demands that do not comply with a pre-specified minimum standard.

Water resources system models provide additional information which usually does not reach decision makers because of its highly complex and technical nature. The system modeller could easily determine if the lack of reliability in any given demand should be corrected with new water supply sources, infrastructure for water regulation or transport, or demand management, but conveying this information to decision makers is usually a daunting task (Grigg 1996). It is helpful to develop indices to summarize and transfer the results to the decision maker. Indices will also allow for comparisons of different systems and, therefore, are useful tools to objectively establish priorities. The four indices proposed in next section meet these requirements for this decision oriented approach.

\subsection{The Demand-Reliability Curve}

In this work, reliability is understood as the probability that the system will be able to adequately supply the demand. Demand units can be grouped in several categories or classes, according to the nature of water use. Categories could be, for instance, in-stream environmental use, urban water supply, irrigation, hydropower, industry, recreation, etc. For each category, $k$, an acceptable reliability level, $r_{k}$, is fixed, depending on the requirements of water usage. This level $r_{k}$ may be determined by local law (MMARM 2008, for the Spanish case), by decision makers rules, by stakeholders consensus, or by the analyst himself performing sensitivity analyses.

Model results are the monthly series of amount of water supplied to every demand. For each demand category, model results are analyzed through the Demand-Reliability (DR) curve, which is shown in Fig. 1. The DR curve represents the cumulative value of demands which are supplied with a given reliability or more,

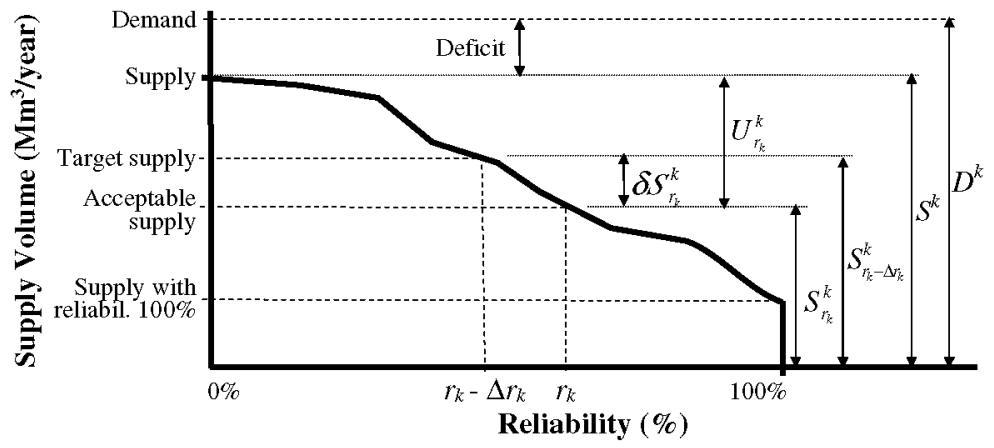

Fig. 1 Demand-Reliability curve (DR curve) 
so that the curve is always decreasing. From this curve, the following representative values are extracted:

- Demand, $D^{k}$ : average water demand in class $k$, in $\mathrm{Mm}^{3} / \mathrm{yr}$. ...

- Supply, $S^{k}$ : average amount of water supplied to demands in class $k$, regardless of reliability, in $\mathrm{Mm}^{3} / \mathrm{yr}$.

- Acceptable supply, $S_{r_{k}}^{k}$ : average amount of water supplied to demands in class $k$ with reliability greater than the acceptable value $r_{k}$, in $\mathrm{Mm}^{3} / \mathrm{yr}$.

- Unacceptable supply, $U_{r_{k}}^{k}$ : average amount of water supplied to demands in class $\mathrm{k}$ with reliability smaller than the acceptable value $r_{k}$, in $\mathrm{Mm}^{3} / \mathrm{yr}$.

Management actions should, in part, be oriented to improve reliability and reduce $U_{r_{k}}^{k}$. According to this, the following magnitudes could also be identified in the DR curve:

- Improved supply, $\delta S_{r_{k}}^{k}=$ average amount of water supplied to demands in class $k$ below the acceptable reliability level $r_{k}$, but that could reach that acceptable level $r_{k}$ through management actions or minor infrastructures of local scope, in $\mathrm{Mm}^{3} / \mathrm{yr}$. This value may be obtained by new simulations or calculated by local managers.

- Target for reliability improvement, $\Delta r_{k}=$ reliability increment that corresponds to the improved supply $\delta S_{r_{k}}^{k}$.

- Target supply, $S_{r_{k}-\Delta r_{k}}^{k}$ : average amount of water supplied to demands in class $k$ that are below the acceptable reliability $r_{k}$, but within $\Delta r_{k}$ to reach it through management actions or minor infrastructures of local scope, in $\mathrm{Mm}^{3} / \mathrm{yr}$.

\subsection{Demand Satisfaction Index: $I_{s}$}

This index evaluates the system's capacity to supply its demands. For each class $k$, the index is computed as the ratio between water supplied and water demanded:

$$
I_{S}^{k}=\frac{S^{k}}{D^{k}}
$$

The demand satisfaction index for the system is computed as the weighted mean of the indices of each class. Two weights are used in the computation: the relative weight and the relevance weight. The relative weight, $\alpha_{k}$, is computed as the fraction of the class demand in all system demands:

$$
\alpha_{k}=\frac{D^{k}}{\sum_{i=1}^{i=K} D^{i}}=\frac{D^{k}}{D_{T}}
$$

where $K$ is the number of classes and $D_{T}$ is the total demand, in $\mathrm{Mm}^{3} / \mathrm{yr}$.

The relevance weight, $\beta_{k}$, is assigned subjectively, depending on the objectives of basin policy. Demand classes which are considered more important in basin management should have the higher $\beta_{k}$ values. Relevance weights should be assigned with the constraint that the sum of the products of relative and relevance weights for all classes in the system should be one:

$$
\sum_{i=1}^{i=K} \alpha_{i} \beta_{i}=1
$$


The value of the demand satisfaction index for the entire system is computed as a weighted average of class values:

$$
I_{S}=\sum_{i=1}^{i=K} \alpha_{i} \beta_{i} I_{S}^{i}
$$

Numerical values of $I_{S}$ are equal to or lower than 1 . As higher is the value of this index, the system is less vulnerable to droughts, since vulnerability is related to the magnitude of damages which are produced due to unsatisfied demand. The reasons for this water scarcity (demand excess, lack of regulation works, inadequate management, conflict with nonconsumptive demands, etc.) can be analysed with the help of the remaining indices. For the case study, the results of sensitivity analyses performed suggest that values of $I_{S}$ below 0.7 should be qualified as unfavourable, while they should not be qualified as favourable until they are over 0.85 .

\subsection{Demand Reliability Index: $I_{R}$}

This index quantifies the reliability of the system to satisfy demands. For each class $k$, the index is computed as the ratio between demand supplied with acceptable reliability and water demand:

$$
I_{R}^{k}=\frac{S_{r_{k}}^{k}}{D^{k}}
$$

The index value for the entire system is computed as:

$$
I_{R}=\sum_{i=1}^{i=K} \alpha_{i} \beta_{i} I_{R}^{i}
$$

Numerical values of this index are always equal to or lower than those of the demand satisfaction index. A high value of $I_{R}$ means great probability that the demands be satisfied any given year. These are reliable or robust systems, which can supply their demands even during drought years. A low value of $I_{R}$ means that the system is not reliable to satisfy its demands and is prone to water scarcity, even in droughts of moderate intensity. The results of sensitivity analyses performed for the case study suggest that values below 0.6 should be qualified as unfavourable, while they should not be qualified as favourable until they are over 0.75 .

\subsection{Sustainability Index: $I_{U}$}

This index evaluates the natural resources available for development in the system. It can only be computed for the entire system, as the ratio between water not allocated to demands and natural flow in the system:

$$
I_{U}=\frac{Y-\sum_{i=1}^{i=K} S^{i}}{Y}=1-\frac{S_{T}}{Y}
$$

where $Y$ is average flow of water resources under natural conditions, in $\mathrm{Mm}^{3} / \mathrm{yr}$. 
Values of this index could in theory be lower than 0 , due to irrigation returns and water recycling, although this situation is extremely unlikely. Low values of this index mean high usage of natural resources. These systems may be prone to water scarcity because of demand excess. High values of this index mean little resource usage, which usually corresponds to systems with little economic development (low population, irrigation, and industry). These systems have proportionately greater water surplus, which will be available for additional uses in the same or in neighbouring basins. Water scarcity in these systems can usually be overcome with regulation works. The threshold value between high and low values is basin-specific, and should be higher for small systems and for systems with irregular streamflow regime. For the basins in the case study (sizes below $10,000 \mathrm{~km}^{2}$ and irregular streamflow regime), threshold values between 0.5 and 0.4 were used.

\subsection{Management Potential Index: $I_{M}$}

This index quantifies the proportion of the demand with unacceptable reliability that is close to the acceptable level. For each class, the index is computed as a ratio. The numerator is the quantity $\delta S_{r_{k}}^{k}$ (see Fig. 1), which is the difference between demand supplied close (within $\Delta r_{k}$ ) to the acceptable reliability level and demand supplied with acceptable reliability level. The denominator is the quantity $U_{r_{k}}^{k}$, which is the demand supplied with unacceptable reliability level:

$$
I_{M}^{k}=\frac{\delta S_{r_{k}}^{k}}{U_{r_{k}}^{k}}=\frac{S_{r_{k}-\Delta r_{k}}^{k}-S_{r_{k}}^{k}}{S^{k}-S_{r_{k}}^{k}}
$$

The index value for the entire system is computed as:

$$
I_{M}=\sum_{i=1}^{i=K} \alpha_{i} \beta_{i} I_{M}^{i}
$$

Values of this index are irrelevant for systems with high values of the demand reliability index $I_{R}$. For the rest of the cases, a high value of $I_{M}$ means that a great proportion of the demand which does not have acceptable reliability, is close to being adequately satisfied. Water scarcity in these systems can be overcome with additional infrastructure, usually of local scope. On the contrary, low values of $I_{M}$ suggest that the demand with unacceptable reliability is far from being satisfied. These systems require actions of greater importance to cope with water scarcity.

The threshold value between high and low depends on $\Delta r_{k}$. It can be suggested, based on the sensitivity analyses performed for the case study for $\Delta r_{k}=5 \%$, that value of the index above 0.1 should be considered high.

\section{Scarcity Analysis in Water Resources Systems Based on the Indices}

The indices defined above are numerical values that can be used for the objective diagnosis of problems in water resources systems. To simplify the decision-making process, numerical values for $I_{S}$ and $I_{R}$ are classified in three qualitative categories in the domain (favourable, neutral, unfavourable) and numerical values for $I_{U}$ and $I_{M}$ are classified in two qualitative categories (high, low). 


\subsection{Objective Classification of Index Values}

Subjective thresholds to classify index values could be defined for a well-known system based on the analyst's experience, or be supplied externally by the decision-maker. But a simple procedure is proposed to compare several systems to identify the more problematic cases and to establish action priorities. The procedure consists of computing the weighted mean, $\bar{I}$, and the weighted standard deviation, $\Delta I$, of the index values, $I$, of the systems (where $I$ represents any of the above indices $I_{S}, I_{R}, I_{U}$ or $I_{M}$ ):

$$
\begin{gathered}
\bar{I}=\sum_{j=1}^{j=S} \gamma_{j} I^{j} \\
\Delta I=\sqrt{\frac{\sum_{j=1}^{j=S}\left(\gamma_{j} I^{j}-\bar{I}\right)^{2}}{S-1}}
\end{gathered}
$$

where $\gamma_{s}$ is the relative weight of each system, and $S$ is the number of systems. Relative weights can be proportional to natural flow, basin area, system demand, or any other objective quantity that characterises the system's size.

According to this procedure, the intervals for values of indices $I_{S}$ and $I_{R}$ are defined as favourable: $(\bar{I}+\Delta I / 2,1]$, neutral: $[\bar{I}-\Delta I / 2, \bar{I}+\Delta I / 2]$, or unfavourable: $[0, \bar{I}-\Delta I / 2)$, and of indices $I_{U}$ and $I_{M}$ are defined as high: $[\bar{I}, 1]$ or low: $[0, \bar{I})$.

\subsection{Analysis Based on the Indices}

This section proposes a framework for the combined use of the qualitative index values to characterize water resources systems, assessing the intensity of potential water scarcity, diagnosing the nature of problems, and proposing the corresponding solutions.

According to problems, systems have been classified in three main groups: vulnerable, unreliable and unsustainable. Vulnerable systems are those where deficit is high compared to demand. In these systems important damages can be produced by water scarcity, either during a temporary drought or due to clime change. Unreliable systems are those where a significant number of demands do not reach the required reliability. These systems are prone to suffer significant impacts even in the case of low intensity droughts. Unsustainable systems are those that have an excessive demand compared to mean annual flow. These systems are frequently exposed to water scarcity situations because of the irregularity of natural flows. Vulnerable, unreliable and unsustainable systems are identified through low values of the demand satisfaction, reliability and sustainability indices respectively.

Solutions can be adopted from the supply or demand side. The proposed solutions to increment supply are based on incrementing yield through the addition of reservoir storage to the system or bringing additional water resources to the system. The spatial scope of storage measures can be local or global, and the regulation can be done within-the-year or over-the-year. Additional resources may come from within-the-system through internal connections, from outside-the-system through inter-basin water transfers, from groundwater, and from non-conventional resources such as water recycling or desalinization. On the demand side, solutions may focus on demand management or on mitigating the impacts. Demand management includes actions that pursue to increase water efficiency and to reduce 
excess of demand. Impact mitigation includes drought contingency plans, conjunctive use of surface and groundwater, insurance policies, etc.

Table 1 shows the problems for each combination of index values, and the suggested solutions for every case. Necessarily problems and solutions have been greatly simplified. In general, vulnerable systems do not have enough resources to meet their demands and they require actions to increase the available resources, either from their own basins of from external basins, or to reduce demands. Unreliable systems generally require structural actions to consolidate water supply to demands, such as local regulation or transportation works, or non-structural actions to mitigate drought impacts. When these problems coincide with low values of the sustainability index $I_{U}$, actions should primary focus on the demand side, trying to improve water conservation by reducing losses, increasing water efficiency, encouraging water recycling, and making different demands compatible. The management potential index $I_{M}$ gives an idea of the size of the actions to be carried out, which should be greater for low values of this index.

\section{Case Study}

To validate practical usefulness, the above methodology was applied to a real case study: the Ebro river basin. This basin was selected because of the availability of the basic data required for the study. The Ebro basin, located on the northeast of the Iberian Peninsula, is the largest basin in Spain, with an area of $85,000 \mathrm{~km}^{2}$ and a mean annual flow of $18,200 \mathrm{Mm}^{3} / \mathrm{yr}$. It supplies water to $2,700,000$ people, around 800,000 ha of irrigated land, and industrial demands totalling over $400 \mathrm{Mm}^{3} / \mathrm{yr}$. There are more than 300 hydropower plants. A further 2 nuclear and 5 conventional power plants use Ebro water for refrigeration. Demands are expected to increase in the future (irrigated area will reach 1,300,000 ha in 20 years' time).

Table 1 Systems characterisation as a function of index values

\begin{tabular}{|c|c|c|c|c|c|c|c|c|}
\hline & \multicolumn{2}{|c|}{$I_{S} \uparrow$} & \multicolumn{2}{|c|}{$\boldsymbol{I}_{S}=$} & \multicolumn{2}{|c|}{$I_{S} V$} \\
\hline & & & Problem & Solution & Problem & Solution & Problem & Solution \\
\hline \multirow{2}{*}{$I_{R} \Uparrow$} & \multicolumn{2}{|l|}{$I_{U^{+}}$} & & & 1 & B1 & 1 & $\mathrm{~B} 2-\mathrm{C} 1$ \\
\hline & \multicolumn{2}{|l|}{$I_{U}=$} & & & 1 & A-B1 & $1-3$ & $\mathrm{~A}-\mathrm{B} 2-\mathrm{C} 2$ \\
\hline \multirow{4}{*}{$I_{R}=$} & \multirow{2}{*}{$\boldsymbol{I}_{U^{+}}$} & $I_{M}+$ & 2 & $\mathrm{D}$ & $1-2$ & B1 & $1-2$ & $\mathrm{~B} 2-\mathrm{Cl}$ \\
\hline & & $I_{M}=$ & 2 & $\mathrm{D}$ & $1-2$ & B2 & $1-2$ & $\mathrm{~B} 3-\mathrm{Cl}$ \\
\hline & \multirow{2}{*}{$\boldsymbol{I}_{U}-$} & $\boldsymbol{I}_{M}+$ & 2 & $A-D$ & $1-2$ & $\mathrm{~A}-\mathrm{B} 1$ & $1-2-3$ & $A-B 2-C 2$ \\
\hline & & $I_{M}-$ & 2 & $A-D$ & $1-2$ & $\mathrm{~A}-\mathrm{B} 2$ & $1-2-3$ & $\mathrm{~A}-\mathrm{B} 3-\mathrm{C} 2$ \\
\hline \multirow{4}{*}{$I_{R} \downarrow$} & \multirow{2}{*}{$\boldsymbol{I}_{U^{+}}+$} & $I_{M}+$ & 2 & B1-D & $1-2$ & $\mathrm{~B} 2-\mathrm{C} 1$ & $1-2$ & $\overline{\mathrm{B} 3-\mathrm{C} 1}$ \\
\hline & & $I_{M}-$ & 2 & B1 - D & $1-2$ & $\mathrm{~B} 3-\mathrm{C} 1$ & $1-2$ & $\mathrm{~B} 3-\mathrm{C} 1$ \\
\hline & \multirow{2}{*}{$\boldsymbol{I}_{U^{-}}$} & $\boldsymbol{I}_{M}+$ & $2-3$ & $\mathrm{~A}-\mathrm{B} 1-\mathrm{D}$ & $1-2-3$ & $\mathrm{~A}-\mathrm{B} 2-\mathrm{C} 2$ & $1-2-3$ & $A-B 3-C 2$ \\
\hline & & $\boldsymbol{I}_{M}-$ & $2-3$ & $\mathrm{~A}-\mathrm{B} 1-\mathrm{D}$ & $1-2-3$ & $\mathrm{~A}-\mathrm{B} 3-\mathrm{C} 2$ & $1-2-3$ & $\mathrm{~A}-\mathrm{B} 3-\mathrm{C} 2$ \\
\hline \multirow{2}{*}{\multicolumn{9}{|c|}{$\begin{array}{l}\text { Index values: } \uparrow \text { favourable }=\text { neutral } \quad \text { unfavourable }+ \text { high }- \text { low } \\
\text { Problems: 1. Vulnerable: water scarcity may produce important damages. 2. Unreliable: low intensity } \\
\text { droughts may lead to water scarcity. 3. Excess of demand with respect to natural resources } \\
\text { Solution }\end{array}$}} \\
\hline & & & & & & & & \\
\hline \multicolumn{5}{|c|}{$\begin{array}{l}\text { A. Demand management } \\
\text { B. Regulation works: } 1 \text { local within-year, } \\
2 \text { global within-year, } 3 \text { global over-year }\end{array}$} & \multicolumn{4}{|c|}{$\begin{array}{l}\text { C. Water transfers: } 1 \text { internal, } 2 \text { external or complement. } \\
\text { resources (groundwater, desalination, etc.) } \\
\text { D. Non-structural actions to mitigate impacts }\end{array}$} \\
\hline \multicolumn{3}{|c|}{ Problem intensity: } & None & Medium & Serious & Very se & & \\
\hline
\end{tabular}


Management of water resources for the entire Ebro basin has been analysed with the help of 28 simulation models. These models were created for the Ebro River Water Plan (CHE 1998). Every model simulates an independent system, formed by a single tributary to the Ebro river or by several tributaries connected by infrastructures that allow global management. Once the models were calibrated for the current scenario, two future scenarios were analysed: one corresponding to mid-term (10 years) and other corresponding to long-term (20 years). The current scenario corresponds to the present situation of demands, resources, infrastructures and management strategies, as stated in the Ebro River Water Plan. The midterm scenario introduces new demands and the most urgent actions of infrastructures and management strategies to be carried out within 10 years scope. The long-term scenario introduces additional demands, infrastructures and management strategies to reach the final development situation of the basin, that should be carried out within 20 years scope. All the future demands and infrastructures for the mid-term and long-term scenarios are defined in the Ebro River Water Plan, that was approved in by law in 2001 and later modified in 2005.

Time series of monthly natural flows used in the models correspond to a historic period of 46 years, and were computed with a rainfall-runoff model. Current and planned infrastructures (reservoirs, channels, hydropower plants, etc.) and current and forecasted demands (urban supply, irrigation, industrial, etc.) were considered. Non consumptive demands like environmental flows, hydropower, fish farms, power plant refrigeration, recreational, etc., were also included in the models, because they are a restriction to system operation, although they were not included in the index computations.

\subsection{Index Computations}

Index computations were limited to those systems that are independent from the rest, that is, that their demands are supplied with their own resources. Very large systems were also disregarded (should be subdivided), since average values could obscure relevant local features, and only systems with less than $10,000 \mathrm{~km}^{2}$ were analysed. Of the 28 systems in the Ebro river basin, the 17 systems shown in Table 3 satisfy the previous requirements. Indices for these systems were computed using the equations provided above. Required data were obtained from the results of the corresponding simulation models. Index values are obtained for to the current situation and for the mid-term and long-term future scenarios. For each scenario, the indices of every system have been computed from the corresponding DR curve. An example of these curves is shown in Fig. 2 for the current scenario of system 17: Jalón. The representative values of these tables are shown in Table 2. There have been
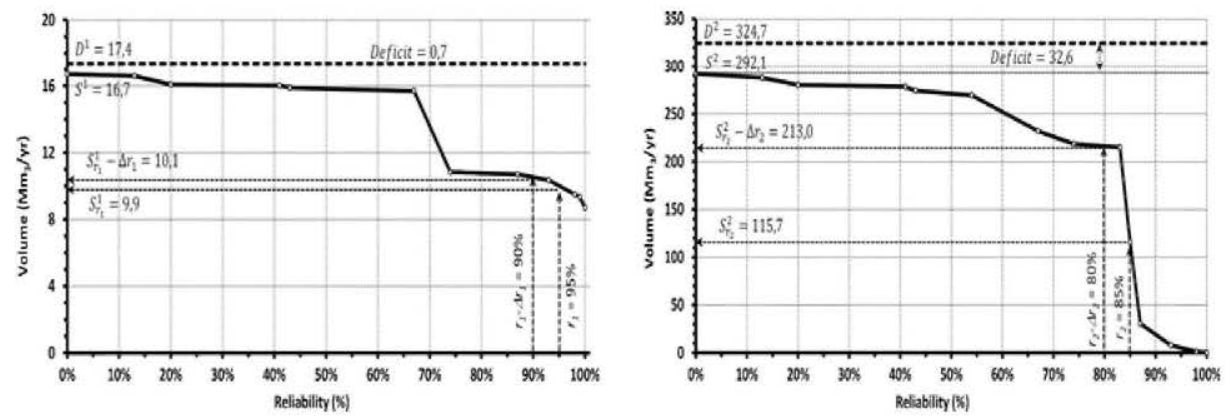

Fig. 2 DR curves for the system 17, Jalón, in the current scenario. The curve on the left corresponds to demand class $k=1$, urban water supply, and the curve on the right corresponds to demand class $k=2$, irrigation 
Table 2 Representative values from the DR curves in the current scenario for system 17, Jalón

\begin{tabular}{|c|c|c|c|c|c|c|c|c|c|c|}
\hline System & $\begin{array}{l}D^{l} \\
\mathrm{Mm}^{3}\end{array}$ & $\begin{array}{l}D^{2} \\
\mathrm{Mm}^{3}\end{array}$ & $\begin{array}{l}S^{l} \\
\mathrm{Mm}^{3}\end{array}$ & $\begin{array}{l}S^{2} \\
\mathrm{Mm}^{3}\end{array}$ & $\begin{array}{l}S_{95 \%}^{l} \\
\mathrm{Mm}^{3}\end{array}$ & $\begin{array}{l}S_{85 \%}^{2} \\
\mathrm{Mm}^{3}\end{array}$ & $\begin{array}{l}S_{90 \%}^{l} \\
\mathrm{Mm}^{3}\end{array}$ & $\begin{array}{l}S_{80 \%}^{2} \\
\mathrm{Mm}^{3}\end{array}$ & $\begin{array}{l}\alpha_{1} \\
\%\end{array}$ & $\begin{array}{l}\alpha_{2} \\
\%\end{array}$ \\
\hline 17. Jalón & 17.4 & 324.7 & 16.7 & 292.1 & 9.9 & 115.7 & 10.1 & 213.0 & 5.1 & 94.9 \\
\hline
\end{tabular}

adopted the values for acceptable reliability decided by the managers of the basin: for urban supply $r_{1}=95 \%$ and for irrigation $r_{2}=85 \%$. Also, the values for improved supply that correspond to the calculated target reliability improvement are $\Delta r_{1}=4.96 \%$ and $\Delta r_{2}=$ $5.04 \%$. The relative weights $\alpha_{1}$ and $\alpha_{2}$ are computed as in Eq. (2) and the relevance weights are 1 in both cases.

The resulting indices for system 17, Jalón, and for all the other systems are presented in Table 3. The values of indices which fall below the qualitative classification of favorable given in Table 4 are highlighted.

\subsection{Diagnostic of Ebro Water Resources Systems}

The analysis of water scarcity begins with the definition of intervals for the qualitative classification of the indices. Values were provided by the basin authority (Confederación Hidrográfica del Ebro, $\mathrm{CHE}$ ) after a sensitivity analysis: since the dominant component of demand is irrigation, values of $I_{S}>0.9$ and $I_{R}>0.8$ were considered favourable, while values of $I_{S}<0.75$ and $I_{R}<0.6$ were considered unfavourable. The thresholds for $I_{U}$ and $I_{M}$ (for $\Delta r_{k}=5 \%$ ) were set in 0.40 and 0.05 respectively. In addition, a comparative analysis among all systems was performed by the above described procedure, using as weights the average natural flow of every system. Results are shown in Table 4.

Once the indices of every system had been classified in qualitative categories, problems were diagnosed for every system and solutions were identified by applying the general

Table 3 Indices results for the water resources systems of the case study

\begin{tabular}{|c|c|c|c|c|c|c|c|c|c|c|c|c|c|}
\hline \multirow{3}{*}{$\begin{array}{c}\text { Water } \\
\text { Resources } \\
\text { System }\end{array}$} & Flow & \multicolumn{4}{|c|}{ Current scenario } & \multicolumn{4}{|c|}{ Mid-term scenario } & \multicolumn{4}{|c|}{ Long- term scenario } \\
\hline & $Y$ & $I_{S}$ & $I_{R}$ & $I_{U}$ & $I_{M}$ & $I_{S}$ & $I_{R}$ & $I_{U}$ & $I_{M}$ & $I_{S}$ & $I_{R}$ & $I_{U}$ & $I_{M}$ \\
\hline & $\mathrm{Mm}^{3}$ & $\%$ & $\%$ & $\%$ & $\%$ & $\%$ & $\%$ & $\%$ & $\%$ & $\%$ & $\%$ & $\%$ & $\%$ \\
\hline 1. Nela & 526.7 & 98 & 96 & 98 & - & 99 & 98 & 98 & - & 99 & 98 & 97 & - \\
\hline 2. Jerea & 127.8 & 100 & 100 & 100 & - & 100 & 100 & 97 & - & 100 & 100 & 97 & - \\
\hline 3. Omecillo & 139.6 & 95 & 71 & 97 & 2 & 96 & 78 & 96 & 0 & 96 & 83 & 95 & - \\
\hline 4. Ega & 492.5 & 85 & 57 & 93 & 0 & 99 & 91 & 90 & - & 100 & 100 & 77 & - \\
\hline 5. Rudrón & 112.6 & 100 & 100 & 100 & - & 100 & 100 & 100 & - & 100 & 100 & 100 & - \\
\hline 6. Oca & 155.2 & 97 & 81 & 98 & - & 98 & 88 & 97 & - & 98 & 93 & 94 & - \\
\hline 7. Oroncillo & 19.4 & 88 & 84 & 84 & - & 88 & 84 & 84 & - & 89 & 85 & 84 & - \\
\hline 8. Tirón & 286.1 & 93 & 64 & 87 & 0 & 99 & 97 & 71 & - & 100 & 98 & 63 & - \\
\hline 9. Najerilla & 402.4 & 93 & 89 & 83 & - & 99 & 99 & 78 & - & 99 & 94 & 74 & - \\
\hline 10. Iregua & 209.6 & 98 & 37 & 53 & 0 & 100 & 100 & 52 & - & 100 & 100 & 45 & - \\
\hline 11. Leza & 71.8 & 84 & 54 & 89 & 0 & 84 & 54 & 89 & 0 & 99 & 99 & 87 & - \\
\hline 12. Cidacos & 85.2 & 67 & 22 & 72 & 5 & 99 & 98 & 38 & - & 99 & 98 & 38 & - \\
\hline 13. Arba & 172.8 & 87 & 50 & 82 & 0 & 86 & 52 & 80 & 0 & 98 & 95 & 72 & - \\
\hline 14. Alhama & 134.8 & 59 & 7 & 58 & 2 & 62 & 34 & 54 & 2 & 83 & 69 & 40 & 28 \\
\hline 15. Queiles & 57.6 & 65 & 30 & 25 & 19 & 65 & 22 & 0 & 0 & 68 & 23 & 0 & 0 \\
\hline 16. Huecha & 22.8 & 40 & 0 & 39 & 0 & 49 & 0 & 15 & 0 & 47 & 0 & 11 & 4 \\
\hline 17. Jalón & 551.3 & 90 & 37 & 39 & 52 & 95 & 89 & 36 & - & 94 & 87 & 29 & - \\
\hline
\end{tabular}


Table 4 Qualitative classification of index values

\begin{tabular}{|c|c|c|c|c|c|c|c|c|c|c|}
\hline \multirow[t]{2}{*}{ Criterion } & \multicolumn{3}{|l|}{$I_{S}(\%)$} & \multicolumn{3}{|l|}{$I_{R}(\%)$} & \multicolumn{2}{|c|}{$I_{U}(\%)$} & \multicolumn{2}{|c|}{$I_{M}(\%)$} \\
\hline & Fav. & Neutral & Unfav. & Fav. & Neutral & Unfav. & High & Low & High & Low \\
\hline CHE & $100-90$ & $90-75$ & $75-0$ & $100-80$ & $80-60$ & $60-0$ & $\geq 40$ & $<40$ & $\geq 5$ & $<5$ \\
\hline Comparative & $100-89$ & $89-77$ & $77-0$ & $100-57$ & $57-21$ & $21-0$ & & & & \\
\hline Adopted & $100-90$ & $90-77$ & $77-0$ & $100-80$ & $80-60$ & $60-0$ & & & & \\
\hline
\end{tabular}

criteria presented in Table 1. Results of the diagnostic, focused on decision support, are presented in Table 5.

All results were validated through interviews with basin authority managers. The interviews were carried out with several managers of the Ebro River Basin Authority: the Head of the Planning Office and the chief executive managers of the 17 water resources systems analyzed. The problems and solutions that result from the application of the methodology were shown to system managers and compared with the actual measures they had adopted in the Ebro River Water Plan. In general, a good agreement was obtained with the conclusions of the technical studies carried out for the Ebro River Water Plan. In fact, the lines of action contemplated in the Plan practically coincide with the guidelines provided here. For instance, in the current scenario of system Jalón, the methodology proposes solutions A (demand management), B1 (local regulation works) and D (impact mitigation actions). The Water Plan for this system includes for the mid-term scenario the construction of two

Table 5 System diagnostics

\begin{tabular}{|c|c|c|c|c|c|c|}
\hline \multirow{2}{*}{ System } & \multicolumn{2}{|c|}{ Current scenario } & \multicolumn{2}{|c|}{ Mid-term scenario } & \multicolumn{2}{|c|}{ Long-term scenario } \\
\hline & Problem & Solution & Problem & Solution & Problem & Solution \\
\hline \multicolumn{7}{|l|}{1 Nela } \\
\hline \multicolumn{7}{|l|}{2 Jerea } \\
\hline 3 Omecillo & 2 & D & 2 & $\mathrm{D}$ & & \\
\hline $4 \mathrm{Ega}$ & $1-2$ & B3 - C1 & & & & \\
\hline \multicolumn{7}{|l|}{5 Rudrón } \\
\hline \multicolumn{7}{|l|}{$6 \mathrm{Oca}$} \\
\hline 7 Oroncillo & 1 & B1 & 1 & B1 & 1 & B1 \\
\hline 8 Tirón & 2 & D & & & & \\
\hline \multicolumn{7}{|l|}{9 Najerilla } \\
\hline 10 Iregua & \multirow{2}{*}{$\begin{array}{l}2-3 \\
1-2\end{array}$} & \multirow{2}{*}{$\begin{array}{c}\mathrm{A}-\mathrm{B} 1-\mathrm{D} \\
\mathrm{B} 3-\mathrm{C} 1\end{array}$} & & & & \\
\hline 11 Leza & & & $1-2$ & B3 - C1 & & \\
\hline 12 Cidacos & $1-2$ & $\mathrm{~B} 3-\mathrm{C} 1$ & & & & \\
\hline 13 Arba & $1-2$ & $\mathrm{~B} 3-\mathrm{C} 1$ & $1-2$ & $\mathrm{~B} 3-\mathrm{Cl}$ & & \\
\hline 14 Alhama & $1-2-3$ & $\mathrm{~A}-\mathrm{B} 3-\mathrm{C} 2$ & $1-2-3$ & $\mathrm{~A}-\mathrm{B} 3-\mathrm{C} 2$ & $1-2$ & $\mathrm{~A}-\mathrm{B} 1$ \\
\hline 15 Queiles & $1-2-3$ & $\mathrm{~A}-\mathrm{B} 3-\mathrm{C} 2$ & $1-2-3$ & $\mathrm{~A}-\mathrm{B} 3-\mathrm{C} 2$ & $1-2-3$ & $A-B 3-C 2$ \\
\hline 16 Huecha & $1-2-3$ & $\mathrm{~A}-\mathrm{B} 3-\mathrm{C} 2$ & $1-2-3$ & $\mathrm{~A}-\mathrm{B} 3-\mathrm{C} 2$ & $1-2-3$ & $A-B 3-C 2$ \\
\hline 17 Jalón & $2-3$ & $\mathrm{~A}-\mathrm{B} 1-\mathrm{D}$ & & & & \\
\hline \multicolumn{7}{|c|}{$\begin{array}{l}\text { Problems: 1. Vulnerable: water scarcity may produce important damages. 2. Unreliable: low intensity } \\
\text { droughts may lead to water scarcity. 3. Excess of demand with respect to natural resources } \\
\text { Solution }\end{array}$} \\
\hline \multicolumn{3}{|c|}{$\begin{array}{l}\text { A. Demand management } \\
\text { B. Regulation works: } 1 \text { local within-year, } \\
2 \text { global within-year, } 3 \text { global over-year }\end{array}$} & \multicolumn{4}{|c|}{$\begin{array}{l}\text { C. Water transfers: } \mathbf{1} \text { internal, } 2 \text { external or complement. } \\
\text { resources (groundwater, desalination, etc.) } \\
\text { D. Non-structural actions to mitigate impacts }\end{array}$} \\
\hline Problem intensity & \multicolumn{2}{|c|}{ None } & \multicolumn{2}{|c|}{ Serious } & erious & \\
\hline
\end{tabular}


reservoirs of local scope (Mularoya and Lechago) and a program to improve water use efficiency in the irrigation districts. Although it was not part of the Plan, a drought management plan was later implemented as a mitigation action. These measures are expected to solve the problems in the Jalón system for the mid-term scenario, although its sustainability index decreases (and so for the long-term scenario) because the area under irrigation is expected to increase in the system. This good agreement, that also occurs for the other systems of the Ebro, validates the proposed methodology and proves the usefulness of the indices presented here as aggregate descriptors of the situation of a water resources system, encouraging its application to other basins.

\section{Conclusions}

Four indices were presented to be used in conjunction, in order to characterize the behaviour of water resources systems with respect to water scarcity. In systems affected by water scarcity problems, the indices can also propose guidelines for solutions. The indices were conceived as an assistance tool to decision making in water resources planning. Indices are computed using simple mathematical relations, so that their meaning is intuitive for their target users. Required data for index computations can be easily obtained from the results of water resources simulation models. Therefore, indices can also be used to summarize and transfer the results obtained from the models.

Criteria were given to interpret index values, focusing the analysis on decision support to establish lines of action in a context of proactive drought management. The analysis can lead to conclusions about the reliability and vulnerability of systems to water scarcity, as well as help to diagnose their possible causes and to propose solutions. In cases where several systems are analysed, indices are also useful to make a comparative study between systems and to prioritize actions.

The described methodology was applied to the Ebro river basin, computing index values for 17 water resources systems and identifying existing or expected problems and possible solutions in each one. System diagnostics, based exclusively on the analysis of index values, were compared with the known reality as perceived by system managers, validating the conclusions in all cases.

\section{References}

Cai X, McKinney DC, Lasdon LS (2002) A framework for sustainability analysis in water resources management and application to the Syr Darya Basin. Water Resour Res 38(6). doi:10.1029/ 2001WR000214

CHE (1998) Plan Hidrológico de la cuenca del Ebro, Confederación Hidrográfica del Ebro. http:// www.chebro.es/contenido.visualizar.do?idContenido $=6923$ \&idMenu $=2240$ (original in Spanish)

Garen DC (1993) Revised Surface Water Supply Index (SWSI) for Western United States. J Water Resour Plan Manag-ASCE 119(4):437-454

Grigg NS (1996) Management framework for large-scale water problems. J Water Resour Plan Manag-ASCE 122(4):296-300

Guttman NB (1998) Comparing the palmer drought index and the standardized precipitation index. J Am Water Resour As 34(1):113-121

Hashimoto T, Sstedinger JR, Loucks DP (1982) Reliability, resiliency, and vulnerability criteria for waterresource system performance evaluation. Water Resour Res 18(1):14-20

Hsu SK (1995) Shortage indices for water-resources planning in Taiwan. J Water Resour Plan Manag-ASCE 121(2):119-131 
Loucks DP (1997) Quantifying trends in system sustainability. Hydrol Sci J 42(4):513-530. doi:10.1080/ 02626669709492051

McKee TB, Doesken NJ, Kleist J (1993) The relationship of drought frequency and duration to time scales. 8th Conference on Applied Climatology, Anaheim, CA

MMARM (2008) Ministerio de Medio Ambiente, y Medio Rural y Marino, Orden ARM/2656/2008, de 10 de septiembre, por la que se aprueba la Instrucción de Planificación Hidrológica (original in Spanish)

Ohlsson L (2000) Water conflicts and social resource scarcity. Phys Chem Earth Part B- Hydrol Oceans Atmos 25(3):213-220

Quiring SM, Papakryiakou TN (2003) An evaluation of agricultural drought indices for the Canadian prairies. Agric For Meteorol 118(1-2):49-62

Shafer BA, Dezman LE (1982) Development of a surface water supply index (SWSI) to assess the severity of drought conditions in snowpack runoff areas. Proc Western Snow Conference:164-175

Wilchfort O, Lund JK (1997) Shortage management modelling for urban water supply systems. J Water Resour Plan Manag-ASCE 123(4):250-258 